\title{
Cinética de fermentação ruminal in vitro da forrageira Brachiaria brizantha cv. Marandu em sistema silvipastoril
}

[Kinetics of in vitro ruminal fermentation of Brachiaria brizantha cv. Marandu in silvopastoral system]

\author{
L.F. Sousa ${ }^{1}$, R.M. Maurício ${ }^{2}$, L.C. Gonçalves ${ }^{3}$, I. Borges $^{3}$, G.R. Moreira ${ }^{4}$ \\ ${ }^{1}$ Departamento de Zootecnia - UFT - Palmas, TO \\ ${ }^{2}$ Departamento de Bioengenharia - UFSJ - São João Del Rei, MG \\ ${ }^{3}$ Escola de Veterinária - UFMG - Belo Horizonte, MG \\ ${ }^{4}$ Aluno de pós-graduação - EV-UFMG - Belo Horizonte, MG
}

\begin{abstract}
RESUMO
No bioma cerrado, nos anos de 2006 e 2007, estudou-se a influência do sistema silvipastoril composto pela arbórea bolsa-de-pastor (Zeyheria tuberculosa) sobre a cinética de fermentação ruminal in vitro da gramínea Brachiaria brizantha cv. Marandu. O sistema silvipastoril foi estabelecido em 1982, em latossolos vermelho-amarelo pela regeneração natural da espécie arbórea. No ensaio de cinética de fermentação ruminal in vitro, usou-se o delineamento inteiramente ao acaso, em parcelas subdivididas, sendo as parcelas o sistema silvipastoril e o monocultivo de B. brachiaria, e as subparcelas os períodos de colheita durante o ano, com três repetições por tratamento. A cinética de fermentação ruminal foi equivalente entre os sistemas estudados. Na estação das chuvas, as forrageiras foram mais fermentáveis do que nos períodos de transição. As forrageiras colhidas no período seco apresentaram menor fermentabilidade.
\end{abstract}

Palavras-chave: nutrição animal, pastagens, sombreamento

\begin{abstract}
The influence of a silvopastoral system composed of Bolsa de Pastor (Zeyheria tuberculosa) on in vitro kinetics of ruminal fermentation of Brachiaria brizantha cv. Marandu was evaluated at Cerrado bioma, in the years 2006 and 2007. The silvopastoral was established in 1982, by natural regeneration of tree species in red-yellow oxisols. The trials on kinetics of ruminal fermentation were carried out in a splitplot design with three replicates. The silvopastoril system and the monoculture of Brachiaria were allocated as plots and the harvest periods as the split-plots. Kinetics of ruminal fermentation in the systems were similar. However, during the rainy season, the forage was highly fermentable in comparison to the transition season. The forage harvested during the dry season showed lower fermentability.
\end{abstract}

Keywords: animal nutrition, pastures, shading

\section{INTRODUÇÃO}

Os sistemas agroflorestais, em suas diferentes modalidades, agrossilviculturais, agrossilvipastoris e silvipastoris, são opções agroecológicas que incluem em seus conceitos referências aos principais componentes da sustentabilidade, ou seja, o econômico, o social e o ambiental (Macedo et al., 2000). Os sistemas silvipastoris são associações de espécies florestais exóticas e nativas com plantas forrageiras herbáceas ou rasteiras e animais herbívoros, que buscam a sustentabilidade de pastagens naturais e cultivadas, além de obter múltiplos produtos vegetais e animais, como madeira, carne e leite (Carvalho et al., 2001). 
Em sistemas de produção em pasto, é de fundamental importância conhecer o valor nutritivo das forrageiras (Euclides et al., 2009). $\mathrm{O}$ conceito do termo valor nutritivo refere-se à composição bromatológica do alimento, sua cinética de fermentação ruminal, sua digestibilidade aparente da energia e seu consumo voluntário por ruminantes (Crampton et al., 1960; Mott, 1970). Por isso, é de grande relevância para a nutrição animal o conhecimento dos teores bromatológicos, da cinética de fermentação ruminal e da digestibilidade in vitro da matéria seca, quando se iniciam as avaliações de uma forrageira em um sistema de produção em pasto (Mott, 1970; Ørskov et al., 1980; Nunes et al., 1985).

A técnica in vitro semiautomática de produção de gases (Maurício et al., 1999) apresenta comprovado potencial em descrever a cinética da fermentação no rúmen e em determinar a taxa e a extensão da degradação das forrageiras (Getachew et al., 1998), bem como medir produtos da fermentação de partes solúveis e insolúveis de substratos (Pell e Schofield, 1993; Castro et al., 2010). Essa técnica permite avaliar grande número de substratos por experimento, apresentando alta acurácia nas medições, simplicidade no manuseio de equipamentos e baixo custo na implantação e por amostra analisada.

O objetivo deste estudo foi avaliar a cinética de fermentação ruminal da gramínea Brachiaria brizantha cv. Marandu, sob influência da arbórea, bolsa-de-pastor (Zeyheria tuberculosa Vell. Bur.) durante o ano agrícola de 2006-2007 - novembro/06 a novembro/07 - na região de cerrado do município de Lagoa Santa, MG, por meio da técnica in vitro semiautomática de produção de gases.

\section{MATERIAL E MÉTODOS}

O experimento foi realizado em um sistema silvipastoril (Ssp), localizado na fazenda Grota Funda, nas seguintes coordenadas geográficas: 19², 35', 36" Sul, 43ㅇ 51', 56" Oeste; altitude, $747 \mathrm{~m}$, correspondente ao bioma cerrado, no município de Lagoa Santa, estado de Minas Gerais (Viana et al., 2002). A arbórea bolsa-de- pastor (Zeyheria tuberculosa Vell. Bur.) foi escolhida e utilizada para formação de um sistema de produção florestal visando, inicialmente, à produção de madeira. O sistema foi desenvolvido em 1982, em latossolo vermelho-amarelo, pela regeneração natural, utilizando-se da técnica de roçada seletiva, que consiste em eliminar, por meio de roçado, as espécies não desejadas, tendo como regra de seleção da densidade arbórea a manutenção de uma distância mínima de quatro metros entre árvores, o que resultou na densidade arbórea de 160 árvores/ha (Viana et al., 2002).

A gramínea plantada substituiu uma pastagem de capim-jaraguá (Hiparrhenia rufa). A implantação foi feita no ano de 1990 utilizandose tração animal, fertilizantes - fosfato natural e calcário -, e sementes de Brachiaria brizantha cv. Marandu, que foram esparramadas a lanço entre as árvores no Ssp e na área a pleno sol. A área não foi queimada, e, desde então, foi utilizada como fonte de forragem para os bovinos de corte e leite (Viana et al., 2002). As árvores de Z tuberculosa mediam de 17 a $28 \mathrm{~m}$ de altura, com diâmetro à altura do peito de 40 a $60 \mathrm{~cm}$. O experimento foi composto por um sistema arborizado e seu respectivo controle (monocultura de Brachiaria brizantha cv. Marandu, a pleno sol, sem sombreamento).

No começo da estação chuvosa do ano de 2006 (25 de novembro), fez-se um corte de uniformização a $30 \mathrm{~cm}$ do solo, quando a forrageira de cada área, repetição, atingiu 60 $80 \mathrm{~cm}$. Foram retiradas três amostras por unidade experimental (arremesso do quadrado $1 \mathrm{x} 1 \mathrm{~m}$ ), colhidas com auxílio de pequenas foices a $30 \mathrm{~cm}$ do solo. As áreas, correspondentes às repetições dos tratamentos, de $4 \times 4 \mathrm{~m}\left(16 \mathrm{~m}^{2}\right)$, foram localizadas por meio de sorteio e cercadas para que não houvesse interferência dos animais em pastejo na área. Tal procedimento está de acordo com Silva (1995), que preconiza como manejo correto a entrada de animais na pastagem quando a planta estiver com 60 a $80 \mathrm{~cm}$ de altura média do relvado, e a sua retirada quando estiver com 30 a $40 \mathrm{~cm}$. Antes de cada corte, foi medida a altura média do relvado, com a utilização de uma trena. Isso resultou em sete cortes, como se pode observar na Tab. 1. 
Tabela 1. Períodos experimentais de corte

\begin{tabular}{lccc}
\hline Período & Estação & Data & Número de dias \\
\hline P1 & Chuva & (24 de nov. a 25 de dez. - 2006) & 31 \\
P2 & Chuva & (26 de dez. a 25 de jan. - 2007) & 31 \\
P3 & Chuva & (26 de jan. a 25 de fev. - 2007) & 31 \\
P4 & Chuva & (26 de fev. a 28 de mar. - 2007) & 31 \\
P5 & Transição chuva-seca & (29 de mar. a 28 de abr. - 2007) & 31 \\
P6 & Seca & (29 de abr. a 28 de jul. - 2007) & 92 \\
P7 & Transição seca-chuva & (29 de jul. a 23 de nov. - 2007) & 118 \\
\hline
\end{tabular}

Após o corte, as amostras de forragem foram levadas ao laboratório, onde foram secas em estufa de circulação forçada a $55^{\circ} \mathrm{C}$, moídas em moinho tipo Willye com peneiras de $1 \mathrm{~mm}$ e acondicionadas em recipientes plásticos identificados para posteriores análises. Foram determinados os teores de matéria seca (MS) (Official.., 1995), matéria mineral (MM) e matéria orgânica (MO). Para os ensaios de produção de gases e degradabilidade, utilizou-se a técnica in vitro semiautomática de produção de gases (Maurício et al., 1999). Para tal, em frascos $(160 \mathrm{~mL})$, previamente acrescidos de $\mathrm{CO}_{2}$, foram adicionadas amostras de forragem (1g), secas e moídas a $1 \mathrm{~mm}$. O meio de cultura (Theodorou et al., 1994) foi adicionado a cada frasco, o qual, posteriormente, foi lacrado com rolha de silicone e levado para a geladeira $\left(4^{\circ} \mathrm{C}\right)$. As incubações foram feitas em triplicatas. Os frascos brancos, sem substrato, contendo só inóculo, também foram incubados para corrigir a liberação de gases proveniente da fermentação de resíduos do inóculo. Antes da incubação, os frascos foram mantidos em estufa, por doze horas, para atingirem a temperatura de incubação de $39^{\circ} \mathrm{C}$.

O líquido ruminal (inóculo) foi colhido de um bovino macho da raça Jersey, doador, fistulado no rúmen, antes do fornecimento da alimentação matinal, com dieta calculada para atender às exigências de mantença e manter $o$ peso constante, tendo como volumoso básico o feno de tifton (Cynodon spp.) e como concentrado base uma formulação comercial com $18 \%$ de proteína bruta. Após a coleta, o líquido ruminal foi acondicionado em garrafas térmicas de $2 \mathrm{~L}$ e levado ao laboratório.

O inóculo, 10mL, injetado em frascos, foi levado à estufa $\left(39^{\circ} \mathrm{C}\right)$ até a primeira leitura. As leituras de pressão foram realizadas em intervalos preestabelecidos de dois, quatro, seis, oito, 10, 12, 15, 19, 24, 30, 34, 48, 72 e 96 horas, inserindo uma agulha fixada a um transdutor de pressão. As leituras foram transformadas em volume de gases pela equação definida por Maurício et al. (2003):

$\mathrm{V}=\left(0,051 \times \mathrm{P}^{2}\right)+(4,43 \times \mathrm{P})-(0,004)$, em que:

$\mathrm{V}=$ volume em $\mathrm{mL}$;

$\mathrm{P}=$ pressão dada por libra por polegada quadrada, ou pound square inch (PSI).

No tempo final da incubação, 96 horas, a fermentação foi interrompida e os frascos foram colocados em geladeira a $4^{\circ} \mathrm{C}$. A degradabilidade da matéria seca (DMS) foi obtida pela filtragem dos resíduos da fermentação em cadinhos (porosidade 1) forrados com lã de vidro e posterior secagem em estufa $\left(100^{\circ} \mathrm{C}\right)$ para determinação do resíduo. Pela diferença dos resíduos (cinzas) da queima em mufla $\left(600^{\circ} \mathrm{C}\right)$ se estimou a degradabilidade da matéria orgânica (DMO).

O delineamento estatístico dos ensaios foi o inteiramente ao acaso em parcelas subdivididas, sendo as parcelas os dois sistemas - silvipastoril e monocultivo - e as subparcelas os sete períodos de corte (P1 a P7), quatro na época chuvosa (P1 a P4), um na transição (chuva-seca) (P5), um na seca (P6) e um na transição (seca-chuva) (P7), e três repetições por tratamento.

As comparações das médias dos resultados dos parâmetros foram feitas pelo teste de Skott-Knott com $5 \%$ de probabilidade. O modelo estatístico adotado foi:

Yijk $=\mu+S i+e_{(a)} i+P j+S P j i+e_{(b)} i j$, em que:

$\mu$ é a média geral;

Si é o efeito do sistema i, i = 1, 2;

$\mathrm{e}_{(\mathrm{a})} \mathrm{i}$ é o erro tipo a;

Pj é o efeito do período de corte j, j = 1, 2, 3,...,7;

SPij é o efeito da interação sistema versus período de corte;

$\mathrm{e}_{(\mathrm{b})} \mathrm{ij}$ é a erro tipo b. 
Os dados cinéticos de produção de gases e degradabilidade foram submetidos à análise de regressão pelo programa estatístico SAS/1989 e regredidos de acordo com o modelo de France et al. (1993):

$Y=A \times\left\{1-\exp ^{[-b(t-L)-c \times(\sqrt{ } t-\sqrt{ } L)]}\right\}$, em que:

$\mathrm{Y}$ é a produção acumulativa de gases $(\mathrm{mL})$;

A é a máxima produção acumulada de gases $(\mathrm{mL})$;

L é a tempo de colonização (h);

$b \quad\left(\mathrm{~h}^{-1}\right)$ e $c\left(\mathrm{~h}^{-0,5}\right)$ são as taxas fracionais constantes;

t é o tempo (h).

As equações oriundas dessas análises de regressão foram comparadas pelo teste de paralelismo e identidade de curvas, descrito por Freese (1970).

A taxa fracional média $\left(\mathrm{h}^{-1}\right)$ de produção de gases $(\mu)$ foi calculada como:

$\mu=\frac{b+c}{2 \sqrt{ } t}$, em que:

$\mu$ é a taxa de produção de gases $\left(\mathrm{h}^{-1}\right)$, e os demais termos definidos anteriormente.

A degradabilidade efetiva foi estimada por meio de dados da produção de gases e da degradabilidade in vitro com 96 horas de incubação, utilizando-se o MLP (Ross, 1980). A taxa de passagem para o cálculo de degradabilidade efetiva foi $k=0,02$, que é a indicada para alimentos volumosos (Ørskov, 1980).

\section{RESULTADOS E DISCUSSÃO}

Nas Tab. 2 e 3, são apresentados os dados de produção máxima acumulada de gases (A) e da taxa de produção de gases $(\mathfrak{l})$, respectivamente, obtidas por meio da técnica in vitro semiautomática de produção de gases (Maurício et al., 1999), no processo de fermentação da forrageira do Ssp e monocultino (Mono), nos diversos períodos experimentais. $\mathrm{O}$ período de colheita teve efeito significativo $(\mathrm{P}<0,05)$ sobre os parâmetros de fermentação, sendo que este efeito foi semelhante nos dois sistemas. Em todos os períodos estudados, tanto a produção máxima acumulada de gases quanto a taxa de produção de gases do processo de fermentação da forrageira não diferiram entre os sistemas $(\mathrm{P}>0,05)$.

Estes resultados diferem dos observados por Sousa et al. (2007), que relataram redução da máxima produção de gases acumulada, em resposta ao sombreamento de $74 \%$. Porém, Sousa (2005), ao trabalhar com um sistema com intensidade de sombreamento semelhante, 62\%, também não encontrou efeito significativo do sombreamento sobre os parâmetros de fermentação da forrageira.

No início da estação chuvosa, P1 e P2, os valores foram significativamente mais altos que os encontrados no final da estação chuvosa, P3 e P4. Estes, por sua vez, foram mais elevados que os dos períodos de transição, P5 e P7, e o menor valor correspondeu à colheita feita no auge da estação seca, P6.

Tabela 2. Produção máxima acumulada de gases obtida pela técnica in vitro semiautomática de produção de gases, no processo de fermentação da forrageira dos sistemas silvipastoril (Ssp) e monocultivo (Mono), nos diversos períodos experimentais (P)

\begin{tabular}{|c|c|c|c|c|c|c|c|c|c|}
\hline \multirow{2}{*}{ Sistema } & \multicolumn{7}{|c|}{ Produção máxima acumulada de gases(mL) } & \multirow{2}{*}{ Média } & \multirow{2}{*}{$\begin{array}{l}\mathrm{CV}_{\text {(a) }} \\
(\%)\end{array}$} \\
\hline & P1 & P2 & P3 & P4 & P5 & P6 & P7 & & \\
\hline Ssp & 199,05D & $198,87 \mathrm{D}$ & $189,42 \mathrm{C}$ & $189,84 \mathrm{C}$ & $179,35 B$ & $171,95 \mathrm{~A}$ & $182,35 B$ & 187,26 & Q 35 \\
\hline Mono & 199,65D & $200,12 \mathrm{D}$ & $188,94 \mathrm{C}$ & $190,57 \mathrm{C}$ & $181,58 B$ & $172,54 \mathrm{~A}$ & $183,26 \mathrm{~B}$ & 188,09 & 9,35 \\
\hline $\begin{array}{c}\text { Média } \\
\mathrm{CV}_{(\mathrm{b})}(\%)\end{array}$ & 199,35 & 199,50 & 189,18 & $\begin{array}{c}190,21 \\
5,71\end{array}$ & 180,47 & 172,25 & 182,81 & 187,68 & \\
\hline
\end{tabular}

Não houve diferença significativa entre os valores de Ssp e Mono em todos os períodos estudados pelo teste de SkottKnott a 5\% de probabilidade.

Valores acompanhados por letras distintas, na linha, diferem entre si pelo teste Skott-Knott a 5\% de probabilidade. P1 a P4 = períodos de chuva; P5 = período de transição (chuva-seca); P6 = período de seca; P7 = período de transição (seca-chuva). $\mathrm{CV}_{(\mathrm{a})}$ e $\mathrm{CV}_{(\mathrm{b})}=$ coeficientes de variação dos erros a e b, respectivamente. 
Tabela 3. Taxa de produção de gases obtida pela técnica in vitro semiautomática de produção de gases no processo de fermentação da forrageira dos sistemas silvipastoril (Ssp) e monocultivo (Mono), nos diversos períodos experimentais $(\mathrm{P})$

\begin{tabular}{|c|c|c|c|c|c|c|c|c|c|}
\hline \multirow{2}{*}{ Sistema } & \multicolumn{7}{|c|}{ Taxa de produção de gases $\left(\mathrm{h}^{-1}\right)$} & \multirow{2}{*}{ Média } & \multirow{2}{*}{$\begin{array}{c}\mathrm{CV}_{\text {(a) }} \\
(\%)\end{array}$} \\
\hline & $\mathrm{P} 1$ & $\mathrm{P} 2$ & P3 & P4 & P5 & P6 & P7 & & \\
\hline Ssp & $0,0449 \mathrm{D}$ & $0,0464 \mathrm{D}$ & $0,0417 \mathrm{C}$ & $0,0401 \mathrm{C}$ & $0,0355 B$ & $0,0309 \mathrm{~A}$ & $0,0372 B$ & 0,0395 & \\
\hline Mono & $0,0454 \mathrm{D}$ & 0,0459D & $0,0421 \mathrm{C}$ & $0,0417 \mathrm{C}$ & 0,0367B & $0,0311 \mathrm{~A}$ & $0,0363 \mathrm{~B}$ & 0,0399 & 9,81 \\
\hline $\begin{array}{c}\text { Média } \\
\mathrm{CV}_{(\mathrm{b})}(\%)\end{array}$ & 0,0452 & 0,0462 & 0,0419 & $\begin{array}{c}0,0409 \\
7,63\end{array}$ & 0,0361 & 0,0310 & 0,0368 & 0,0397 & \\
\hline
\end{tabular}

Não houve diferença significativa entre os valores de Ssp e Mono em todos os períodos estudados pelo teste de SkottKnott a 5\% de probabilidade.

Valores acompanhados por letras distintas, na linha, diferem entre si pelo teste Skott-Knott a 5\% de probabilidade. P1 a P4 = períodos de chuva; P5 = período de transição (chuva-seca); P6 = período de seca; P7 = período de transição (seca-chuva). $\mathrm{CV}_{(\mathrm{a})}$ e $\mathrm{CV}_{(\mathrm{b})}=$ coeficientes de variação dos erros a e b, respectivamente.

Castro et al. (2007), ao trabalharem com B. brizantha cv Marandu, em condições de pleno sol, com 28 dias de crescimento, relataram valores de máxima produção de gases acumulada de $232 \mathrm{~mL}$ e taxa de produção de gases de 0,032. As diferenças em relação aos valores deste trabalho podem estar relacionadas à altura de corte da forragem, $10 \mathrm{~cm}$ no estudo dos autores citados versus $30 \mathrm{~cm}$ neste ensaio, ou seja, a altura de corte influenciou no total de carboidratos da amostra colhida.

Cone et al. (1999), ao trabalharem com gramínea de clima temperado, Lolium perenne, observaram que, com a proximidade do inverno, ocorre diminuição na taxa de produção de gases e na máxima produção de gases acumulada, semelhante ao ocorrido no presente estudo.

Segundo Van Soest (1994), o envelhecimento da forrageira proporciona aumento da parede celular e diminuição do conteúdo celular na célula vegetal. Concomitantemente, a parede celular apresenta alterações significativas quanto à composição e à estrutura química de seus polímeros, com o envelhecimento da forragem (Hobson e Stewart, 1997), ou seja, os resultados dos parâmetros de fermentação acompanham os dados de constituintes da parede celular (Sousa, 2009). Essas interações resultariam em um processo de fermentação mais lento da forrageira com o avançar da estação das chuvas e a proximidade dos períodos mais secos do ano.

Na Tab. 4, são apresentados os dados de tempo de colonização (TC) obtido pela técnica in vitro semiautomática de produção de gases. O TC do processo de fermentação da forrageira estudada não variou entre os sistemas $(\mathrm{P}>0,05)$, em todos os períodos de estudo.

Tabela 4. Tempo de colonização obtido pela técnica in vitro semiautomática de produção de gases no processo de fermentação da forrageira dos sistemas silvipastoril (Ssp) e monocultivo (Mono) nos diversos períodos experimentais $(\mathrm{P})$

\begin{tabular}{|c|c|c|c|c|c|c|c|c|c|}
\hline \multirow{2}{*}{ Sistema } & \multicolumn{7}{|c|}{ Tempo de colonização (horas:minutos) } & \multirow{2}{*}{ Média } & \multirow{2}{*}{$\begin{array}{l}\mathrm{CV}_{\text {(a) }} \\
(\%)\end{array}$} \\
\hline & P1 & P2 & P3 & P4 & P5 & P6 & P7 & & \\
\hline Ssp & $1: 28 B$ & $1: 29 B$ & $1: 28 B$ & $1: 28 B$ & 1:31B & 2:06A & 1:31B & $1: 34$ & \\
\hline Mono & $1: 28 B$ & $1: 28 B$ & $1: 27 \mathrm{~B}$ & $1: 29 B$ & $1: 32 B$ & $2: 12 \mathrm{~A}$ & $1: 31 \mathrm{~B}$ & $1: 35$ & 16,25 \\
\hline $\begin{array}{c}\text { Média } \\
\mathrm{CV}_{(\mathrm{b})}(\%)\end{array}$ & $1: 28$ & $1: 29$ & $1: 28$ & $\begin{array}{c}1: 29 \\
16,03\end{array}$ & $1: 32$ & $2: 09$ & $1: 31$ & $1: 35$ & \\
\hline
\end{tabular}

Não houve diferença significativa entre os valores de Ssp e Mono em todos os períodos estudados pelo teste de SkottKnott a 5\% de probabilidade.

Valores acompanhados por letras distintas, na linha, diferem entre si pelo teste Skott-Knott a 5\% de probabilidade. P1 a P4 = períodos de chuva; P5 = período de transição (chuva-seca); P6 = período de seca; P7 = período de transição (seca-chuva). $\mathrm{CV}_{(\mathrm{a})}$ e $\mathrm{CV}_{(\mathrm{b})}$ = coeficientes de variação dos erros a e b, respectivamente. 
O período de colheita teve efeito $(\mathrm{P}<0,05)$ sobre o tempo de colonização, sendo que este efeito foi semelhante nos dois sistemas. Mas, diferentemente do ocorrido com os outros parâmetros de fermentação (A e $\mu$ ), somente a forrageira colhida na estação seca, P6, apresentou valores de TC significativamente $(\mathrm{P}<0,05)$ mais altos.

O TC está correlacionado com o início do processo fermentativo. Segundo Nogueira et al. (2006), o TC está relacionado principalmente com o teor de carboidratos (CHO) solúveis das forrageiras. Como na época seca do ano, P6, as forrageiras do gênero Brachiaria apresentam, nas estruturas vegetais acima de $30 \mathrm{~cm}$, teor de $\mathrm{CHO}$ solúveis mais baixo que os do período das chuvas, $\mathrm{P} 1$ a $\mathrm{P} 4$, em razão da migração desses CHO para a base do colmo (Andrade e Marques Neto, 1989; Soares Filho, 1991), os resultados do presente ensaio são pertinentes.

Na Fig. 1 e na Tab. 5, estão apresentados os dados de produção acumulada de gases e os modelos gerados pelas análises de regressão ao modelo de France et al. (1993) dos dados de produção acumulada de gases da forrageira, respectivamente. As curvas de regressão dos dados de produção de gases da forrageira estudada sob o efeito do sombreamento não variaram em relação às do monocultivo, ou seja, as curvas do Ssp e do Mono são paralelas e idênticas $(\mathrm{P}<0,05)$.

O período de colheita teve efeito significativo $(\mathrm{P}<0,05)$ no paralelismo e na equivalência das curvas de regressão, sendo este efeito semelhante nos dois sistemas. O teste de identidade de curvas acompanhou os resultados dos parâmetros do modelo de France et al. (1993) (Tab. 2 a 4), o que já era esperado, pois esses parâmetros originam o modelo.

O teste de paralelismo explicitou que os modelos dos períodos de chuvas, P1 a P4, e do período seco, P6, deram origem a curvas paralelas, ou seja, apresentaram o mesmo padrão de comportamento cinético. Já os modelos dos períodos de transição, P5 e P7, não apresentaram paralelismo com os modelos dos demais períodos.

Tabela 5. Equações geradas pelas análises de regressão ${ }^{1}$ dos dados de produção acumulada de gases da forrageira do sistema silvipastoril (Ssp) e monocultivo (Mono) nos diversos períodos (P) experimentais

\begin{tabular}{|c|c|c|c|c|}
\hline \multirow{3}{*}{ P } & \multicolumn{4}{|c|}{ Sistemas } \\
\hline & Ssp & & Mono & \\
\hline & (1) & $\begin{array}{l}\mathrm{R}^{2} \\
(\%)\end{array}$ & Equação & $\begin{array}{l}\mathrm{R}^{2} \\
(\%)\end{array}$ \\
\hline P1 & 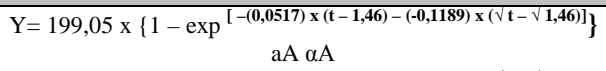 & 99,8 & 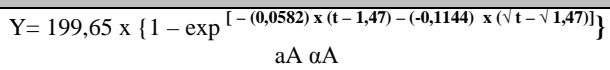 & 99,8 \\
\hline P2 & 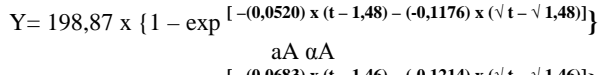 & 99,7 & $Y=200,12 \times\left\{1-\exp \frac{[-(\mathbf{0 , 0 5 7 6}) \times(\mathbf{t}-\mathbf{1}, \mathbf{4 7})-(-\mathbf{0 , 1 1 0 9 )} \times(\sqrt{ } \mathbf{t}-\sqrt{ } \mathbf{1}, \mathbf{4 7})]}{\text { aA } \alpha \mathrm{A}}\right.$ & 99,7 \\
\hline P3 & 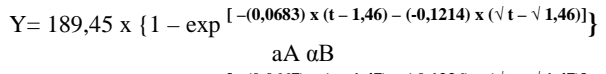 & 99,9 & $Y=188,94 \times\left\{1-\exp \frac{[-(\mathbf{0 , 0 6 6 4}) \times(\mathbf{t}-\mathbf{1 , 4 5})-(-\mathbf{0 , 1 2 0 7 )} \times(\sqrt{ } \mathbf{t}-\sqrt{ } \mathbf{1}, \mathbf{4 5})]}{\mathrm{aA} \alpha \mathrm{B}}\right.$ & 99,9 \\
\hline P4 & $Y=199,84 \times\left\{1-\exp \frac{[-(\mathbf{0 , 0 6 6 7}) \times(\mathbf{t}-\mathbf{1 , 4 7})-(-\mathbf{0 , 1 2 2 6}) \times(\sqrt{ } \mathbf{t}-\sqrt{ } \mathbf{1}, \mathbf{4 7})]}{\mathrm{aA} \alpha \mathrm{B}}\right.$ & 99,8 & $\mathrm{Y}=190,57 \times\left\{1-\exp \frac{[-(\mathbf{0}, \mathbf{0 6 5 4}) \times(\mathbf{t}-\mathbf{1 , 4 8})-(-\mathbf{0 , 1 2 1 2}) \times(\sqrt{ } \mathbf{t}-\sqrt{ } \mathbf{1}, \mathbf{4 8})]}{\mathrm{aA} \alpha \mathrm{B}}\right.$ & 99,7 \\
\hline P5 & 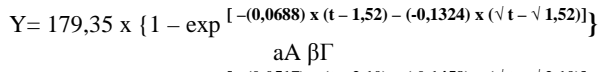 & 99,8 & 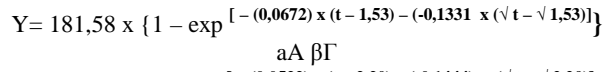 & 99,6 \\
\hline P6 & $\mathrm{Y}=171,95 \times\left\{1-\exp \begin{array}{c}{[-(\mathbf{0}, \mathbf{0 5 1 7}) \times(\mathbf{t}-\mathbf{2 , 1 0})-(-\mathbf{0}, \mathbf{1 4 5 9}) \times(\sqrt{ } \mathbf{t}-\sqrt{2} \mathbf{2}, \mathbf{1 0})]} \\
\text { aA } \alpha \Delta\end{array}\right.$ & 99,9 & 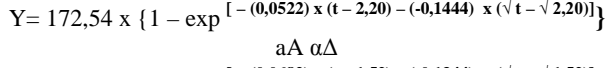 & 99,8 \\
\hline P7 & 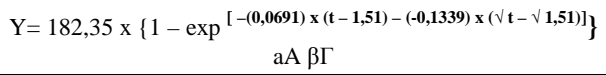 & 99,6 & 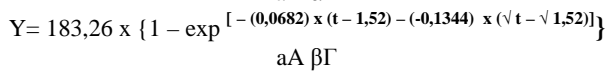 & 99,9 \\
\hline
\end{tabular}

${ }^{1}$ Modelo de France et al. (1993).

Equações acompanhadas por letras minúsculas iguais na mesma linha são paralelas pelo teste de paralelismo de curvas (Freese, 1970) a 5\% de probabilidade; equações acompanhadas por letras maiúsculas iguais na mesma linha são idênticas pelo teste de identidade de curvas (Freese, 1970) a 5\% de probabilidade.

Equações acompanhadas por letras gregas minúsculas iguais na mesma coluna são paralelas pelo teste de paralelismo de curvas (Freese, 1970) a 5\% de probabilidade; equações acompanhadas por letras gregas maiúsculas iguais na mesma coluna são idênticas pelo teste de identidade de curvas (Freese, 1970) a $5 \%$ de probabilidade. $\mathrm{R}^{2}=$ coeficiente de determinação; P1 a P4 = períodos de chuva; P5 = período de transição (chuva-seca); P6 = período de seca; P7 = período de transição (seca-chuva). 


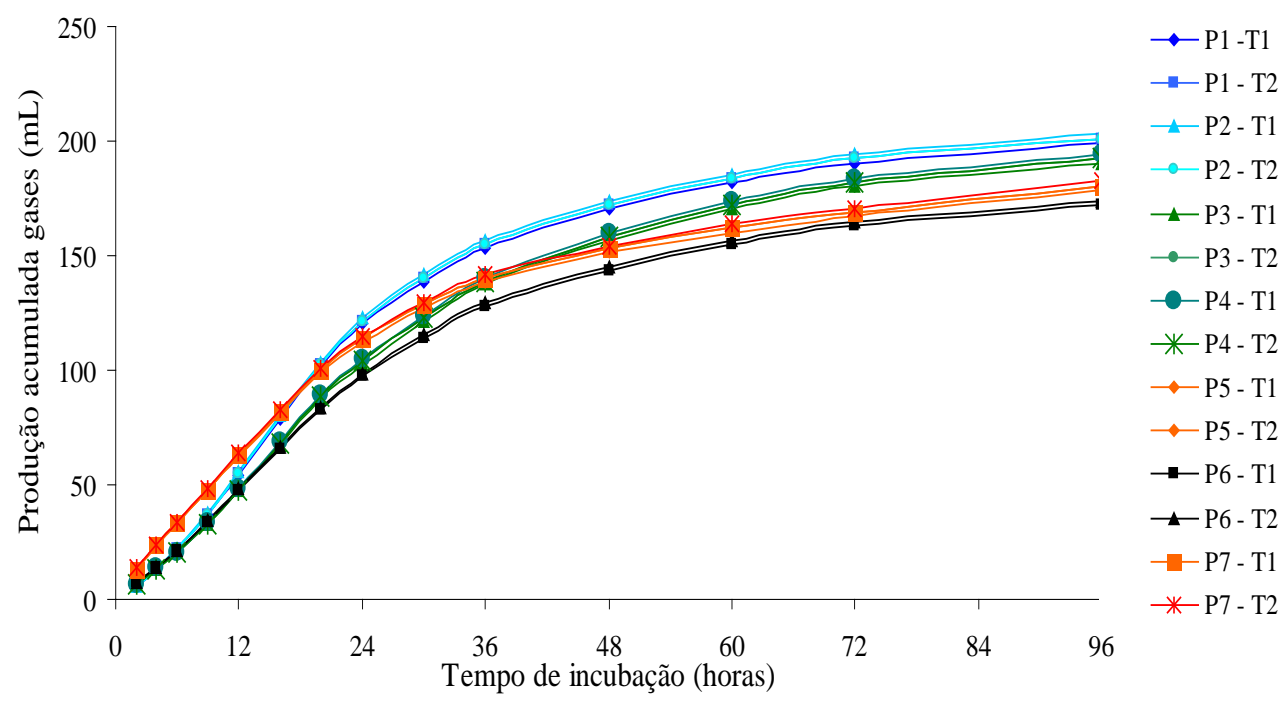

Figura 1. Produção acumulada de gases para $B$. brizantha cv. Marandu do sistema silvipastoril (T1) e monocultivo (T2) nos diversos períodos experimentais $\{\mathrm{P} 1$ a P4 = períodos de chuva; P5 = período de transição (chuva-seca); P6 = período de seca; P7 = período de transição (seca-chuva) .

Não houve diferenças entre as elevações na taxa de fermentação dos $\mathrm{CHO}$ solúveis e $\mathrm{CHO}$ fibrosos de Ssp e Mono, em todos os períodos estudados (Fig. 2). Porém, as elevações nas taxas de fermentação tanto dos CHO solúveis quanto dos CHO fibrosos sofreram influência do período de colheita das forrageiras. Isso ocorreu principalmente em virtude das diferenças existentes nos teores de CHO solúveis de gramíneas forrageiras tropicais nos meses de inverno e verão (Soares Filho, 1991).

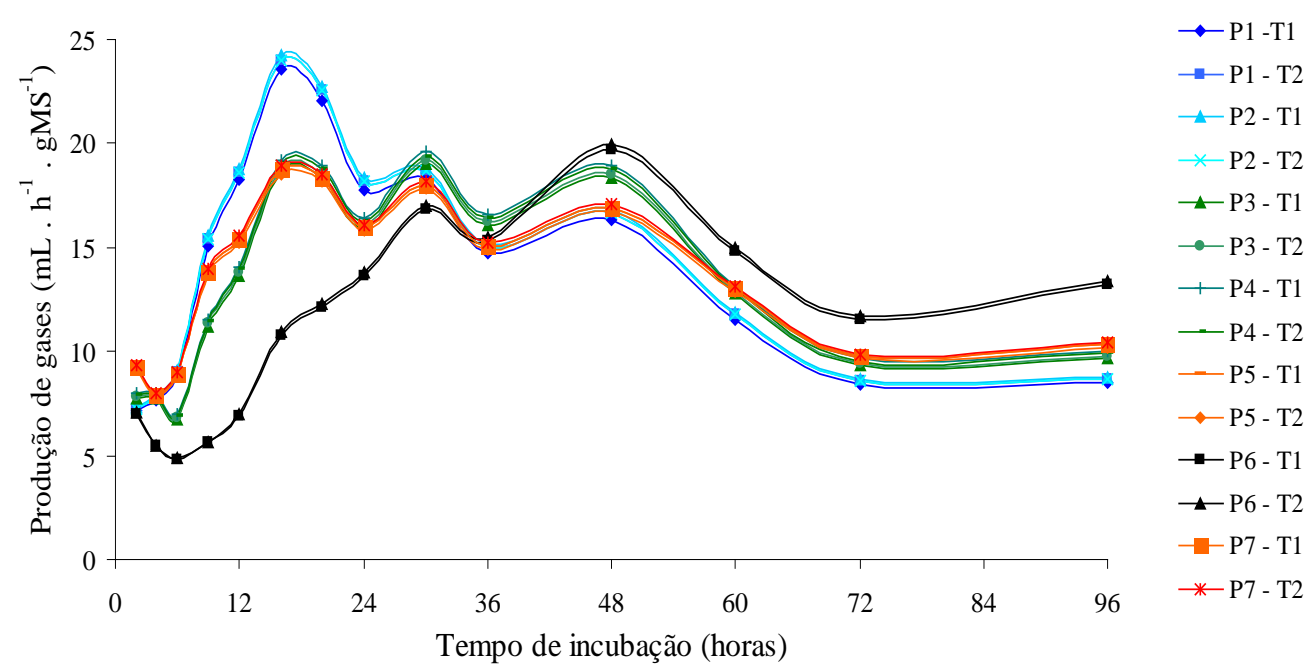

Figura 2. Produção de gases por hora para B. brizantha cv. Marandu dos sistemas silvipastoril (T1) e monocultivo (T2) nos diversos períodos experimentais $\{\mathrm{P} 1$ a $\mathrm{P} 4$ = períodos de chuva; $\mathrm{P} 5$ = período de transição (chuva-seca); P6 = período de seca; P7 = período de transição (seca-chuva)\}. 
Nas Tab. 6 e 7, estão descritos os dados da degradabilidade efetiva da MS (DEMS) e degradabilidade efetiva da MO (DEMO), respectivamente, da forrageira dos sistemas Ssp e Mono, nos diversos períodos experimentais. O sombreamento natural não influenciou a degradabilidade efetiva da $B$. brizantha cv. Marandu, nos diversos períodos experimentais.
Sousa (2005) encontrou valores de degradabilidade efetiva da MS e MO de $42 \%$ e 44\%, respectivamente. Esses valores, muito abaixo dos encontrados neste ensaio, ocorreram em virtude, possivelmente, das diferenças nas taxas de degradação de 0,025 em Sousa (2005) e entre 0,045 e 0,030 no presente ensaio (Tab. 3).

Tabela 6. Degradabilidade efetiva da matéria seca (MS) da forrageira do sistema silvipastoril (Ssp) e monocultivo (Mono) nos diversos períodos experimentais (P)

\begin{tabular}{|c|c|c|c|c|c|c|c|c|c|}
\hline \multirow{2}{*}{ Sistemas } & \multicolumn{7}{|c|}{ Degradabilidade efetiva* da MS (\%) } & \multirow{2}{*}{ Média } & \multirow{2}{*}{$\begin{array}{l}\mathrm{CV}_{\text {(a) }} \\
(\%)\end{array}$} \\
\hline & $\mathrm{P} 1$ & P2 & P3 & $\mathrm{P} 4$ & P5 & P6 & P7 & & \\
\hline Ssp & $67,55 \mathrm{D}$ & $68,97 \mathrm{D}$ & $63,22 \mathrm{C}$ & $62,73 \mathrm{C}$ & $56,91 \mathrm{~B}$ & $50,22 \mathrm{~A}$ & $58,82 B$ & 61,20 & \multirow{2}{*}{5,85} \\
\hline Mono & $69,05 \mathrm{D}$ & $68,07 \mathrm{D}$ & $63,38 \mathrm{C}$ & $64,53 \mathrm{C}$ & $57,93 B$ & $50,71 \mathrm{~A}$ & $57,75 B$ & 61,63 & \\
\hline Média & 68,30 & 68,52 & 63,30 & 63,63 & 57,42 & 50,47 & 58,28 & 61,42 & \\
\hline $\mathrm{CV}_{\text {(b) }}(\%)$ & & & & 4,55 & & & & & \\
\hline
\end{tabular}

Não houve diferença significativa entre os valores de Ssp e Mono em todos os períodos estudados pelo teste de SkottKnott a 5\% de probabilidade.

Valores acompanhados por letras distintas, na linha, diferem entre si pelo teste Skott-Knott a 5\% de probabilidade.

P1 a P4 = períodos de chuva; P5 = período de transição (chuva-seca); P6 = período de seca; P7 = período de transição (seca-chuva). $\mathrm{CV}_{(\mathrm{a})}$ e $\mathrm{CV}_{(\mathrm{b})}=$ coeficientes de variação dos erros a e b, respectivamente. ${ }^{*} \mathrm{k}=0,02$

Tabela 7. Degradabilidade efetiva da matéria orgânica (MO) da forrageira do sistema silvipastoril (Ssp) e monocultivo (Mono) nos diversos períodos experimentais (P)

\begin{tabular}{|c|c|c|c|c|c|c|c|c|c|}
\hline \multirow{2}{*}{ Sistema } & \multicolumn{7}{|c|}{ Degradabilidade efetiva* da MO (\%) } & \multirow{2}{*}{ Média } & \multirow{2}{*}{$\begin{array}{l}\mathrm{CV}_{(\mathrm{a})} \\
(\%)\end{array}$} \\
\hline & P1 & P2 & P3 & $\mathrm{P} 4$ & P5 & P6 & P7 & & \\
\hline Ssp & $70,25 \mathrm{D}$ & $71,73 D$ & $65,75 \mathrm{C}$ & $65,24 \mathrm{C}$ & $59,19 B$ & $52,23 \mathrm{~A}$ & $61,17 \mathrm{~B}$ & 63,65 & \multirow{2}{*}{6,34} \\
\hline Mono & 71,81D & 70,79D & $65,92 \mathrm{C}$ & $66,11 \mathrm{C}$ & $60,25 B$ & $52,74 \mathrm{~A}$ & $60,06 \mathrm{~B}$ & 63,95 & \\
\hline Média & 71,03 & 71,26 & 65,83 & 65,67 & $\overline{59,72}$ & 52,48 & 60,62 & 63,80 & \\
\hline $\mathrm{CV}_{(\mathrm{b})}(\%)$ & & & & 5,24 & & & & & \\
\hline
\end{tabular}

Não houve diferença significativa entre os valores de Ssp e Mono em todos os períodos estudados pelo teste de SkottKnott a 5\% de probabilidade.

Valores acompanhados por letras distintas, na linha, diferem entre si pelo teste Skott-Knott a 5\% de probabilidade.

P1 a P4 = períodos de chuva; P5 = período de transição (chuva-seca); P6 = período de seca; P7 = período de transição (seca-chuva). $\mathrm{CV}_{(\mathrm{a})}$ e $\mathrm{CV}_{(\mathrm{b})}=$ coeficientes de variação dos erros a e b, respectivamente. ${ }^{*} \mathrm{k}=0,02$

\section{CONCLUSÕES}

O sombreamento no Ssp não teve influência nos padrões de fermentação in vitro durante todo o ano. O período de colheita reduziu os padrões de fermentação in vitro, o que resultou em menor produção e qualidade da forrageira nos períodos de transição e inverno.

\section{REFERÊNCIAS BIBLIOGRÁFICAS}

ANDRADE, I.F.; MARQUES NETO, J. Efeito da carga animal sobre os níveis de carboidratos solúveis e pesos seco da base do colmo, base do caule e sistema radicular de Brachiaria decumbens. Rev. Bras. Zootec., v.18, p.426-431, 1989. 
CARVALHO, M.M.; ALVIM, M.J.; CARNEIRO, J.C. (Eds). Sistemas silvipastoris: opções de sustentabilidade para áreas tropicais e subtropicais. Juiz de Fora: Embrapa Gado de Leite, 2001. 414p.

CASTRO, G.H.F.; GRAÇA, D.S.; GONÇALVES, L.C. et al. Cinética de degradação e fermentação ruminal de Brachiaria brizantha cv. Marandu colhida em diferentes idades ao corte Arq. Bras. Med. Vet. Zootec., v.59, p.1538-1544, 2007.

CASTRO, G.H.F.; RODRIGUEZ, N.M.; GONÇALVES, L.C. et al. Características produtivas, agronômicas e nutricionais do capimtanzânia em cinco diferentes idades ao corte. Arq. Bras. Med. Vet. Zootec., v.62, p.654-666, 2010.

CRAMPTON, E.W.; DONEFER, E.; LLOYD, L.E. A nutritive value index for forages. J. Anim. Sci., v.19, p.338-344, 1960.

CONE, J.W.; VAN GELDER, A.H.; DE VISSER, $\mathrm{H}$. et al. Different techniques to study rumen fermentation characteristics of maturing grass and grass silage. J. Dairy Sci., v.62, p.957-966, 1999.

EUCLIDES, V.P.B.; MACEDO, M.C.M.; VALLE, C.B. et al. Valor nutritivo da forragem e produção animal em pastagens de Brachiaria brizantha. Pesq. Agropec. Bras., v.44, p.98-106, 2009.

FRANCE, J.; DHANOA, M.S.; THEODOROU, M.K. et al. A model to interpret gas accumulation profiles with in vitro degradation of ruminant feeds. J. Theor. Biol., v.163, p.99-111, 1993.

FREESE, F. (Ed). Métodos estatísticos elementares para tecnicos forestales. Buenos Aires: Centro Regional de Ayuda tecnica, 1970. 105p. (Manual da Agricultura, 317).

GETACHEW, G.; BLÜMMEL, M.; MAKKAR, H.P.S. et al. In vitro gas measuring techniques for assessment of nutrition quality of feeds: a review. Anim. Feed Sci. Technol., v.72, p.261-281, 1998.

HOBSON, P.N.; STEWART, C.S. (Eds). The rumen microbial ecosystem. London: Brackie Academic \& Professional, 1997. 719p.

MACEDO, R.L.G.; VENTURIN, N.; FILHO, A.A.T. Princípios de agrossilvicultura como subsídio do manejo sustentável. Inf. Agropec., v.21, p.93-98, 2000.

MAURÍCIO, R.M.; MOULD, F.; DHANOA, M.S. et al. A semi-automated in vitro gas production technique for ruminants feedstuff evaluation. Anim. Feed Sci. Technol., v.79, p.321-330, 1999.
MAURÍCIO, R.M; PEREIRA, L.G.R.; GONÇALVES, L.C. et al. Relação entre pressão e volume para implantação da técnica in vitro semiautomática de produção de gases na avaliação de forrageiras tropicais. Arq. Bras. Med. Vet. Zootec., v.55, p.56-61, 2003.

MOTT, G.O. Evaluacion de la produccion de forrajes. In: HUGHES, H.D.; HEATH, M.E.; METCALFE, D.S. (Eds). Forrajes - la ciencia de la agricultura basada en la producción de pastos. México: Continental, 1970. p.131-141.

NOGUEIRA, U.T.; MAURÍCIO, R.M.; GONÇALVES, L.C. Comparação de substratos com diferentes quantidades de carboidratos solúveis utilizando a técnica in vitro semiautomática de produção de gases. Arq. Bras. Med. Vet. Zootec., v.58, p.633-641, 2006.

NUNES, S.G.; BOOCK, A.; PENTEADO, M.I.O. et al. Comissão da cultivar Marandu. Campo Grande: Embrapa Gado de Corte, 1985. 31p. (Documentos, 21).

ØRSKOV, E.R.; HOVELL, F.D.B.; MOULD, F. The use of the nylon bag technique for evaluation of feedstuffs. Trop. Anim. Prod., v.5, p.195-213, 1980.

PELL, A.N.; SCHOFIELD, P. Computerized monitoring of gas production to measure forage digestion in vitro. J. Dairy Sci., v.76, p.1063-1073, 1993.

ROSS, G.J.S. Maximum Likelihood Program (A Manual). Lawes Agricultural Trust. Harpenden,UK: Rothamstead Experimental Station, 1980.

SILVA, S.C. Condições edafoclimáticas para a produção de Panicum sp. In: SIMPÓSIO SOBRE MANEJO DE PASTAGENS, 12., 1995, Piracicaba. Anais... Piracicaba: FEALQ, 1995. p.129-146.

SOARES FILHO, C.V. Variação sazonal de parâmetros bioquímico-fisiológicos em Brachiaria decumbens estabelecida em pastagem. 1991. $110 \mathrm{f}$. Dissertação (Mestrado) - Escola Superior de Agricultura "Luiz de Queiroz" - Universidade de São Paulo. Piracicaba.

SOUSA, L.F. Produtividade e valor nutritivo de Brachiaria brizantha $c v$. Marandu em sistemas silvipastoris. 2005. 61f. Dissertação (Mestrado) Escola de Veterinária, Universidade Federal de Minas Gerais, Belo Horizonte. 
SOUSA, L.F. Brachiaria brizantha $c v$. Marandu em um sistema silvipastoril e monocultivo. 2009. 170f. Tese (Doutorado) - Escola de Veterinária, Universidade Federal de Minas Gerais, Belo Horizonte.

SOUSA, L.F.; MAURÍCIO, R.M.; GONÇALVES, L.C. et al. Produtividade e valor nutritivo da Brachiaria brizantha cv. Marandu em um sistema silvipastoril. Arq. Bras. Med. Vet. Zootec., v.59, p.1029-1037, 2007.

THEODOROU, M.K.; WILLIANS, B.A.; DHANOA, M.S. et al. A simple gas production method using a pressure transducer to determine the fermentation kinetics of ruminant feeds. Anim. Feed Sci. Technol., v.48, p.185-197, 1994.
VAN SOEST, P.J. Nutritional ecology of the ruminant. Ithaca: Cornell University Press, 1994. 476p.

VIANA, V.M.; MAURÍCIO, R.M.; MATTAMACHADO, R. et al. Manejo de la regeneración natural de especies nativas para la formación de sistemas silvopastoriles en las zonas de bosques secos del sureste de Brasil. Agroforesteria em las Américas, v.9, p.48-52, 2002. 